\title{
Clinical Findings of Asymptomatic Carpal Tunnel Syndrome in Patients With Diabetes Mellitus
}

\author{
Hye Young Han, $\mathrm{MD}^{1}$, Ha Min Kim, $\mathrm{MD}^{2}$, So Young Park, $\mathrm{MD}^{1}$, \\ Min-Wook Kim, MD, $\mathrm{PhD}^{1}$, Jae Min Kim, MD, $\mathrm{PhD}^{1}$, Dae-Hyun Jang, $\mathrm{MD}, \mathrm{PhD}^{1}$ \\ ${ }^{1}$ Department of Rehabilitation Medicine, Incheon St. Mary's Hospital, College of Medicine, \\ The Catholic University of Korea, Incheon; ${ }^{2}$ GwangGyo Charm and Good Hospital, Yongin, Korea
}

Objective To evaluate the clinical differences between patients with diabetes mellitus (DM) who have asymptomatic carpal tunnel syndrome (CTS) and those who have symptomatic CTS.

Methods Sixty-three patients with DM were assessed using the Boston Carpal Tunnel Questionnaire (BCTQ), nerve conduction studies (NCS), and ultrasonographic evaluation of the cross-sectional area (CSA) of the median nerve. According to the BCTQ responses and NCS results, the patients were divided into the following three groups: group $1(\mathrm{n}=16)$, in which NCS results did not reveal CTS; group $2(\mathrm{n}=19)$, in which NCS results revealed CTS but the group scored 0 points on the BCTQ (asymptomatic); and group $3(n=28)$, in which NCS results revealed CTS and the group scored $>1$ point on the BCTQ (symptomatic). The clinical findings, NCS results, and CSA of the median nerve were compared among the three groups.

Results There were no significant differences in age, DM duration, glycated hemoglobin levels, and presence of diabetic polyneuropathy among the three groups. The peak latency of the median sensory nerve action potential was significantly shorter in group 1 than in groups 2 and $3(\mathrm{p}<0.001)$; however, no difference was observed between groups 2 and 3. CSA of the median nerve at the carpal tunnel in group 2 was significantly larger than that in group 1 and smaller than that in group $3(\mathrm{p}<0.05)$.

Conclusion The results of our study suggest that the symptoms of CTS in patients with diabetes are related to CSA of the median nerve, which is consistent with swelling of the nerve.

Keywords Asymptomatic diseases, Carpal tunnel syndrome, Diabetes mellitus, Ultrasonography

Received June 8, 2015; Accepted October 13, 2015

Corresponding author: Dae-Hyun Jang

Department of Rehabilitation Medicine, Incheon St. Mary's Hospital, College of Medicine, The Catholic University of Korea, 56 Dongsu-ro, Bupyeonggu, Incheon 21431, Korea. Tel: +82-32-280-5207, Fax:+82-32-280-5040, E-mail: dhjangmd@naver.com

ORCID: Hye Young Han (http://orcid.org/0000-0003-2252-3884; Ha Min Kim (http://orcid.org/0000-0002-6211-6485); So Young Park (http://orcid. org/0000-0002-3547-9547); Min-Wook Kim (http://orcid.org/0000-0003-4505-809X); Jae Min Kim (http://orcid.org/0000-0003-4217-3228); Dae-Hyun Jang (http://orcid.org/0000-0001-8293-084X).

(c) This is an open-access article distributed under the terms of the Creative Commons Attribution Non-Commercial License (http://creativecommons.org/ licenses/by-nc/4.0) which permits unrestricted noncommercial use, distribution, and reproduction in any medium, provided the original work is properly cited. Copyright $\odot 2016$ by Korean Academy of Rehabilitation Medicine 


\section{INTRODUCTION}

Carpal tunnel syndrome (CTS) is the most commonly reported mononeuropathy in patients with diabetes mellitus (DM). Although the prevalence of CTS is $2 \%-3 \%$ among the general population $[1,2]$, its prevalence is approximately $7 \%-16 \%$ in patients with diabetes $[3,4]$. Previous studies have reported DM as a risk factor for CTS $[5,6]$ and identified relationships between the prevalence of CTS and level of hemoglobin Alc (HbAlc), duration of DM, and microvascular complications [7-9]. However, $14 \%-25 \%$ of diabetic patients with CTS do not have clinical symptoms, and it is unclear why this subpopulation does not exhibit the typical signs of nerve entrapment [10].

The diagnosis of CTS is usually based on clinical and electrophysiological findings. Although a nerve conduction study (NCS) is highly specific for the diagnosis of CTS, it can be difficult to differentiate CTS in patients with diabetes and coexisting diabetic polyneuropathy. In recent years, the accuracy of high-resolution diagnostic ultrasonographic equipment has greatly improved. Consequently, the use of ultrasonography for the diagnosis of CTS has been increasing. The most common ultrasonographic findings in patients with nerve entrapment syndrome are sudden flattening of nerves in the zone of entrapment and swelling of the nerve at the proximal edge of the zone of compression [2]. In previous studies, a significant increase in the cross-sectional area (CSA) of the median nerve at the carpal tunnel was the most consistent sonographic finding of CTS $[11,12]$.

In order to investigate the clinical factors associated with the development of symptoms in diabetic patients with CTS, we compared the clinical characteristics and findings, including NCS results and ultrasonographic findings, between diabetic patients with symptomatic CTS and those with asymptomatic CTS.

\section{MATERIALS AND METHODS}

\section{Participants}

The present study was a retrospective investigation of patients with DM greater than 20 years of age who underwent NCS at the electrodiagnostic clinic of Incheon St. Mary's Hospital from June 2011 to November 2014. This study was approved by the Institutional Review Board.
We excluded the patients who had previously undergone surgery for CTS; who had a previous history of trauma and had been diagnosed with fractures of the wrist; who had been diagnosed with cervical radiculopathy, brachial plexopathy, or a focal peripheral neuropathy other than CTS involving the upper extremities; who had medical diseases that could evoke peripheral polyneuropathies other than DM, such as chronic renal insufficiency, chronic alcoholism, toxin exposure, or hypothyroidism. We included a total of 63 dominant hands of diabetic patients, and all patients completed the Boston Carpal Tunnel Questionnaire (BCTQ) and underwent NCS and ultrasonographic evaluation of the median nerve CSA at the carpal tunnel on the same day.

On the basis of the results of these tests, the patients were classified into the following three groups: group 1 $(\mathrm{n}=16)$, in which NCS results did not reveal CTS; group 2 $(\mathrm{n}=19)$, in which NCS results revealed CTS but the group scored 0 points on the BCTQ; and group $3(n=28)$, in which NCS results revealed CTS and the group scored $>1$ point on the BCTQ.

\section{Clinical scale}

Prior to the electrodiagnostic test, a physiatrist administered the BCTQ [13]. This is a self-report scale that assesses the degree of symptom severity and upper extremity function on the basis of the patient's responses according to symptom and functional scale scores. Asymptomatic CTS was defined as a score of 0 points, and symptomatic CTS was defined as a score of $>1$ point following summation of symptom and functional scale scores. The validity and reliability of the BCTQ for the detection of symptom severity and functional status of CTS patients have been confirmed in many studies [14-18]. We used the Korean version of the BCTQ, which has also been shown to have good validity and reliability [19].

\section{Nerve conduction study}

All subjects underwent NCS using an electromyography device (VIASYS Healthcare, Surrey, UK) and surface electrodes (VIASYS Healthcare). The skin temperature of the patients was measured prior to the test, and the temperature of each hand was maintained above $32^{\circ} \mathrm{C}$. Motor conduction studies were performed on the median, ulnar, peroneal, and tibial nerves. F-waves were recorded from the median and tibial nerves. Sensory nerve action 
potentials (SNAPs) were obtained from the median, ulnar, and sural nerves. The median motor response was recorded from the abductor pollicis brevis muscle using supramaximal stimulation $7 \mathrm{~cm}$ from the active electrode; the onset latency and baseline-to-peak amplitude were then measured. The median sensory response was measured antidromically in the third digit, and stimulation was applied at two points: 7 and $14 \mathrm{~cm}$ proximal to the active electrode. The ulnar motor response was recorded from the abductor digiti minimi muscle using stimulation $7 \mathrm{~cm}$ from the active electrode. The ulnar sensory response was measured antidromically in the fifth digit, and stimulation was applied to the wrist $14 \mathrm{~cm}$ proximal to the active electrode. A sensory comparative study of the ring finger was performed when the peak latency of the median SNAP at the wrist was delayed. The electrode was placed over the fourth digit, and stimulations were applied to the median and ulnar sides of the wrist $14 \mathrm{~cm}$ proximal to the active electrode for each position. Bilateral superficial peroneal, sural, deep peroneal, and tibial nerves were also assessed for making the diagnosis of diabetic polyneuropathy (DPN). Superficial peroneal and sural nerves were antidromically recorded $14 \mathrm{~cm}$ distal to the stimulated sites.

CTS was diagnosed according to the American Association of Electrodiagnostic Medicine, American Academy of Neurology, and American Academy of Physical Medicine and Rehabilitation, practice parameters for electrodiagnostic studies in CTS: summary statement [20]. CTS was diagnosed in patients if they met the following criteria: (1) the peak latency of the median SNAP at the wrist $(14 \mathrm{~cm}$ proximal to the active electrode) was delayed $>3.6 \mathrm{~ms}$; (2) the median-to-ulnar peak latency difference at the ring finger ( $14 \mathrm{~cm}$ proximal to the active electrode) was $>0.5 \mathrm{~ms}$; and (3) the wrist-to-palm latency difference was greater than the palm-to-digit latency difference in the median sensory nerve. The diagnosis of DPN was based on the Diabetes Control and Complications Trial [21]. All reference values were based on Dumitru et al.'s description [22].

\section{Ultrasonography}

An experienced Korean physician who was board certified in musculoskeletal ultrasound medicine performed the ultrasound examination using an HD11 XE device (Philips, Bothell, WA, USA) and a 7- to $12-\mathrm{MHz}$ line- array transducer. The physician was blinded to the BCTQ scores and electrodiagnostic results. Ultrasonography was performed while the subject was lying supine with the wrist resting in a neutral position with the palm facing upwards. CSA of the median nerve was measured at the level of the pisiform bone using a direct tracing method within the echogenic boundary of the nerve. If the patient had a bifid median nerve, the summated CSA value of the nerves was used. CSA of the median nerve in each hand was estimated twice, and the mean value was recorded.

\section{Statistical analyses}

All statistical analyses were performed using SPSS ver. 18.0 for Windows (SPSS Inc., Chicago, IL, USA). Normality of the sample was tested by applying the Shapiro-Wilk test. The age and duration of DM were assessed using the Kruskal-Wallis test. HbAlc and the results of NCS were assessed using one-way analysis of variance (ANOVA). Comparisons of the CSA of the median nerve at the carpal tunnel among the three groups were analyzed by Mann-Whitney U test after Kruskal-Wallis test. The rate of DPN was analyzed using the chi-square test, and a pvalue $<0.05$ was considered to indicate statistical significance.

\section{RESULTS}

A total of 63 dominant hands were included in this study: 9 left hands (14.3\%) and 54 right hands (85.7\%). Of the 63 subjects, 17 were male $(27.0 \%)$ and 46 were female $(73.0 \%)$. The mean age was 59 years (range, 29-85 years). The basic characteristics and BCTQ scores of the groups are summarized in Table 1. Multiple comparisons of the variables revealed that the mean age, mean duration of DM, mean value of $\mathrm{HbAlc}$, and rate of coexistence of DPN were not significantly different among the three groups.

The mean peak latency of the median SNAP was significantly shorter in group 1 than in groups 2 and 3 (group 1 , 3.5 $\pm 0.6 \mathrm{~ms}$; group 2, $4.6 \pm 0.6 \mathrm{~ms}$; group $3,5.0 \pm 1.0 \mathrm{~ms}$ ). There was no difference in the mean peak latency of the median SNAP between groups 2 and 3. Similarly, the mean onset latency of the median compound motor action potential (CMAP) was significantly shorter in group 1 than in groups 2 and 3 (group 1, 3.4 $\pm 0.7 \mathrm{~ms}$; group 2, 
Hye Young Han, et al.

Table 1. Baseline characteristics of the three groups ( $n=63)$

\begin{tabular}{lcccccc}
\hline \multicolumn{1}{c}{ Variable } & $\begin{array}{c}\text { Group 1 } \\
(\mathbf{n = 1 6 )}\end{array}$ & $\begin{array}{c}\text { Group 2 } \\
(\mathbf{n = 1 9 )}\end{array}$ & $\begin{array}{c}\text { Group 3 } \\
(\mathbf{n = 2 8})\end{array}$ & \multicolumn{3}{c}{ p-value } \\
\cline { 6 - 7 } & $5: 11$ & $6: 13$ & $6: 22$ & & & \\
\hline Gender (male:female) & $55.9 \pm 15.1$ & $61.2 \pm 11.0$ & $59.9 \pm 12.0$ & 0.226 & 0.554 & 0.465 \\
Age (yr) & $7.4 \pm 9.8$ & $14.2 \pm 12.3$ & $10.3 \pm 8.9$ & 0.068 & 0.084 & 0.406 \\
Duration of DM (yr) & $8.9 \pm 2.5$ & $9.2 \pm 2.6$ & $8.4 \pm 2.3$ & 0.595 & 0.685 & 0.183 \\
HbAlc (\%) & 0 & 0 & $8.4 \pm 6.2$ & & & \\
BCTQ-S & 0 & 0 & $1.9 \pm 2.7$ & & & \\
BCTQ-F & $10(62.5)$ & $12(63.2)$ & $14(50.0)$ & 0.494 & 0.807 & 0.324 \\
\hline DPN & &
\end{tabular}

Values are presented as mean \pm standard deviation or number $(\%)$.

Group 1, no carpal tunnel syndrome with diabetes; group 2, electrodiagnostic carpal tunnel syndrome without symptoms; group 3, electrodiagnostic carpal tunnel syndrome with symptoms; DM, diabetes mellitus; BCTQ-S, Boston Carpal Tunnel Questionnaire symptom scale; BCTQ-F, Boston Carpal Tunnel Questionnaire functional scale; DPN, diabetic polyneuropathy.

Table 2. Results of electrodiagnostic and ultrasonographic studies ( $\mathrm{n}=63)$

\begin{tabular}{lcccccc}
\hline \multicolumn{1}{c}{ Variable } & $\begin{array}{c}\text { Group 1 } \\
(\mathbf{n}=\mathbf{1 6})\end{array}$ & $\begin{array}{c}\text { Group 2 } \\
(\mathbf{n = 1 9 )}\end{array}$ & $\begin{array}{c}\text { Group 3 } \\
(\mathbf{n = 2 8})\end{array}$ & $\begin{array}{c}\text { Group 1 } \\
\text { vs. 2 }\end{array}$ & $\begin{array}{c}\text { Group 1 } \\
\text { vs. 3 }\end{array}$ & $\begin{array}{c}\text { Group 2 } \\
\text { vs. 3 }\end{array}$ \\
\hline $\begin{array}{l}\text { Peak latency of the median } \\
\text { SNAP at the wrist (ms) }\end{array}$ & $3.5 \pm 0.6$ & $4.6 \pm 0.6$ & $5.0 \pm 1.0$ & $<0.001$ & $<0.001$ & 0.356 \\
$\begin{array}{l}\text { Onset latency of the median } \\
\text { CMAP (ms) }\end{array}$ & $3.4 \pm 0.7$ & $4.5 \pm 0.8$ & $4.9 \pm 0.9$ & 0.001 & $<0.001$ & 0.294 \\
$\begin{array}{l}\text { Peak latency of the ulnar } \\
\text { SNAP (ms) }\end{array}$ & $3.5 \pm 0.5$ & $3.6 \pm 0.3$ & $3.4 \pm 0.3$ & 0.311 & 0.880 & 0.102 \\
$\begin{array}{l}\text { Onset latency of the ulnar } \\
\text { CMAP (ms) }\end{array}$ & $2.8 \pm 0.5$ & $3.1 \pm 0.5$ & $2.8 \pm 0.4$ & 0.203 & 0.974 & 0.215 \\
\hline \begin{tabular}{l} 
CSA of the median nerve $\left(\mathrm{mm}^{2}\right)$ \\
\hline
\end{tabular} & $8.6 \pm 1.4$ & $12.5 \pm 2.7$ & $15.5 \pm 4.6$ & $<0.001$ & $<0.001$ & 0.007 \\
\hline
\end{tabular}

Values are presented as mean \pm standard deviation.

Group 1, no carpal tunnel syndrome with diabetes; group 2, electrodiagnostic carpal tunnel syndrome without symptoms; group 3, electrodiagnostic carpal tunnel syndrome with symptoms; SNAP, sensory nerve action potential; CMAP, compound motor action potential; CSA, cross-sectional area.

$4.5 \pm 0.8 \mathrm{~ms}$; group $3,4.9 \pm 0.9 \mathrm{~ms})$. There was no difference in the mean onset latency of the median CMAP between groups 2 and 3. However, the mean peak latency of the ulnar SNAP and the onset latency of the ulnar CMAP were not significantly different among the three groups. The detailed electrodiagnostic findings are listed in Table 2.

The mean CSA of the median nerve at the carpal tunnel in groups 1,2 , and 3 was $8.6,12.5$, and $15.5 \mathrm{~mm}^{2}$, respectively. The mean CSA of the median nerve in group 2 was significantly larger than that in group $1(\mathrm{p}<0.001)$, but it was significantly smaller than that in group $3(\mathrm{p}=0.007)$ (Table 2).

\section{DISCUSSION}

In our study, the mean CSA of the median nerve was larger in diabetic patients with symptomatic CTS than in those with asymptomatic CTS. This is the first study to compare the NCS results and ultrasonographic findings according to the presence of CTS symptoms in patients with diabetes.

Several previous studies have reported that CTS is more prevalent in the population with diabetes $[3,4]$ and DM is a risk factor for CTS $[5,6]$. The increased risk of CTS in patients with diabetes has been attributed to several different etiologies. The median nerves in patients with 
diabetes are vulnerable to focal compression due to endoneurial ischemia [9]. Additionally, increased end products of advanced glycation and myofibroblasts in the connective tissue of the flexor tendon result in synovitis and a thickened flexor retinaculum, which eventually makes the carpal tunnel narrow [23-25]. However, CTS does not always cause clinical symptoms in patients with diabetes. Approximately $14 \%-25 \%$ of diabetic patients with CTS do not exhibit clinical symptoms, and it is unclear why this subpopulation does not display the symptoms of CTS.

Few studies on the clinical characteristics and outcomes of asymptomatic CTS have been reported. Kim et al. [25] reported that $6.8 \%$ of patients with diabetes had asymptomatic electrophysiological CTS and investigated whether the cause of asymptomatic CTS in patients with diabetes was a manifestation of early DPN or an entrapment neuropathy itself. They found that conduction delay in the finger-to-wrist segment was more remarkable in the median nerve than in the ulnar nerve. These results suggest that asymptomatic CTS in patients with diabetes is related to an increased vulnerability to the entrapment of the median nerve rather than to early DPN. Similarly, in our study, there were no differences in the DPN and NCS findings of the ulnar nerve among the three groups.

A study that followed patients with asymptomatic CTS for 11 years found that the probability of developing symptomatic CTS was correlated with differences in the maximum latency during the initial median NCS [26]. Another study reported that $23 \%$ of asymptomatic workers with abnormal median sensory nerve conduction developed symptomatic CTS after an average of 70 months [27]. Although these studies did not specifically evaluate patients with diabetes, their findings indicate that a close observation of asymptomatic CTS patients with diabetes is required.

The putative mechanism of the pathogenesis of asymptomatic CTS in patients with diabetes is an increased sensory threshold $[25,28]$. The density of intraepidermal nerve fibers in the skin of patients with type 2 diabetes has been shown to be negatively associated with the duration of diabetes. Patients with lower density values exhibited higher sensory thresholds [29]. A rodent study found that, compared with subjects with a shorter disease duration, subjects with a longer duration of diabetes tended to exhibit insensate neuropathy rather than painful neuropathy [30]. Thus, there is evidence that the sen- sory threshold can increase in patients with diabetes who have had the disease for a long duration.

In our study, although there were no significant differences in the DM duration and HbAlc values among the three groups, we observed tendencies toward increased DM duration and elevated HbAlc values in the asymptomatic group than in the symptomatic group. These results are believed to be associated with the small sample size used in the present study; therefore, further studies with more patients are required.

CTS patients without diabetes have an increased CSA of the median nerve that is positively correlated with their electrodiagnostic severity $[3,31]$. Similarly, our results showed that the mean peak latency of the median SNAP and mean onset latency of the median CMAP tend to increase in symptomatic patients, although the increase was not significant in the statistical analysis. CSA of the median nerve was significantly increased in symptomatic patients. Because the nerve swelling associated with increasing water content seems to be correlated with a cascade of events that ultimately lead to axonal loss [32], it is possible that CSA of the median nerve is correlated with the severity of CTS.

There were several limitations in the present study. First, the sample size in each group was small. Larger sample sizes may yield more reliable results and greater statistical power. Second, we did not consider the body mass index of the individuals, a factor that can affect CSA of the median nerve. Third, CSA of the median nerve at the proximal forearm and CSA of the ulnar nerve were not measured. Comparison of these values may help to evaluate the swelling of the median nerve more precisely.

Our results for the ultrasonographic findings of the median nerve CSA among the groups suggested that the degree of median nerve swelling may be related to the occurrence of CTS symptoms in patients with diabetes. Therefore, regular ultrasonographic follow-up might be helpful for the prediction of symptom development in patients with diabetes who have been electrophysiologically diagnosed as having CTS but who do not display any symptoms. Further studies with larger sample sizes and significant follow-up periods are required to understand the mechanisms of asymptomatic CTS in patients with diabetes. Such studies may contribute to a better understanding of the underlying pathophysiology of CTS in these patients. 
In conclusion, this study demonstrates that the mean CSA of the median nerve at the carpal tunnel was significantly larger in diabetic patients with symptomatic CTS than in diabetic patients with asymptomatic CTS. Our results suggest that the symptoms of CTS in patients with diabetes may be related to the swelling of the median nerve rather than to the duration of DM, glycemic control, coexistence of DPN, and severity of the values in NCS.

\section{CONFLICT OF INTEREST}

No potential conflict of interest relevant to this article was reported.

\section{REFERENCES}

1. Atroshi I, Gummesson C, Johnsson R, Ornstein E, Ranstam J, Rosen I. Prevalence of carpal tunnel syndrome in a general population. JAMA 1999;282:153-8.

2. Buchberger W, Schon G, Strasser K, Jungwirth W. High-resolution ultrasonography of the carpal tunnel. J Ultrasound Med 1991;10:531-7.

3. Phalen GS. The carpal-tunnel syndrome. Seventeen years' experience in diagnosis and treatment of six hundred fifty-four hands. J Bone Joint Surg Am 1966;48:211-28.

4. Yamaguchi DM, Lipscomb PR, Soule EH. Carpal tunnel syndrome. Minn Med 1965;48:22-33.

5. Geoghegan JM, Clark DI, Bainbridge LC, Smith C, Hubbard R. Risk factors in carpal tunnel syndrome. J Hand Surg Br 2004;29:315-20.

6. Becker J, Nora DB, Gomes I, Stringari FF, Seitensus R, Panosso JS, et al. An evaluation of gender, obesity, age and diabetes mellitus as risk factors for carpal tunnel syndrome. Clin Neurophysiol 2002;113:1429-34.

7. Singh R, Gamble G, Cundy T. Lifetime risk of symptomatic carpal tunnel syndrome in Type 1 diabetes. Diabet Med 2005;22:625-30.

8. Ramchurn N, Mashamba C, Leitch E, Arutchelvam V, Narayanan K, Weaver J, et al. Upper limb musculoskeletal abnormalities and poor metabolic control in diabetes. Eur J Intern Med 2009;20:718-21.

9. Perkins BA, Olaleye D, Bril V. Carpal tunnel syndrome in patients with diabetic polyneuropathy. Diabetes Care 2002;25:565-9.
10. Dyck PJ, Kratz KM, Karnes JL, Litchy WJ, Klein R, Pach JM, et al. The prevalence by staged severity of various types of diabetic neuropathy, retinopathy, and nephropathy in a population-based cohort: the Rochester Diabetic Neuropathy Study. Neurology 1993;43:817-24.

11. Buchberger W, Judmaier W, Birbamer G, Lener M, Schmidauer C. Carpal tunnel syndrome: diagnosis with high-resolution sonography. AJR Am J Roentgenol 1992;159:793-8.

12. Wang LY, Leong CP, Huang YC, Hung JW, Cheung SM, Pong YP. Best diagnostic criterion in high-resolution ultrasonography for carpal tunnel syndrome. Chang Gung Med J 2008;31:469-76.

13. Levine DW, Simmons BP, Koris MJ, Daltroy LH, Hohl GG, Fossel AH, et al. A self-administered questionnaire for the assessment of severity of symptoms and functional status in carpal tunnel syndrome. J Bone Joint Surg Am 1993;75:1585-92.

14. Atroshi I, Johnsson R, Sprinchorn A. Self-administered outcome instrument in carpal tunnel syndrome. Reliability, validity and responsiveness evaluated in 102 patients. Acta Orthop Scand 1998;69:82-8.

15. de Campos CC, Manzano GM, de Andrade LB, Castelo Filho A, Nobrega JA. Translation and validation of an instrument for evaluation of severity of symptoms and the functional status in carpal tunnel syndrome. Arq Neuropsiquiatr 2003;61:51-5.

16. Lue YJ, Lu YM, Lin GT, Liu YF. Validation of the Chinese version of the Boston Carpal Tunnel Questionnaire. J Occup Rehabil 2014;24:139-45.

17. Rosales RS, Delgado EB, Diez de la Lastra-Bosch I. Evaluation of the Spanish version of the DASH and carpal tunnel syndrome health-related quality-of-life instruments: cross-cultural adaptation process and reliability. J Hand Surg Am 2002;27:334-43.

18. Sezgin M, Incel NA, Serhan S, Camdeviren H, As I, Erdogan C. Assessment of symptom severity and functional status in patients with carpal tunnel syndrome: reliability and functionality of the Turkish version of the Boston Questionnaire. Disabil Rehabil 2006;28:1281-5.

19. Park DJ, Kang JH, Lee JW, Lee KE, Wen L, Kim TJ, et al. Cross-cultural adaptation of the Korean version of the Boston carpal tunnel questionnaire: its clinical evaluation in patients with carpal tunnel syndrome 
following local corticosteroid injection. J Korean Med Sci 2013;28:1095-9.

20. Jablecki CK, Andary MT, Floeter MK, Miller RG, Quartly CA, Vennix MJ, et al. Practice parameter: electrodiagnostic studies in carpal tunnel syndrome. Report of the American Association of Electrodiagnostic Medicine, American Academy of Neurology, and the American Academy of Physical Medicine and Rehabilitation. Neurology 2002;58:1589-92.

21 . The effect of intensive diabetes therapy on the development and progression of neuropathy. The Diabetes Control and Complications Trial Research Group. Ann Intern Med 1995;122:561-8.

22. Dumitru D, Amato AA, Zwarts MJ. Electrodiagnostic medicine. 2nd ed. Philadelphia: Hanley \& Belfus; 2002.

23. Thomsen NO, Mojaddidi M, Malik RA, Dahlin LB. Reduced myelinated nerve fibre and endoneurial capillary densities in the forearm of diabetic and nondiabetic patients with carpal tunnel syndrome. Acta Neuropathol 2009;118:785-91.

24. Rosenbloom AL, Silverstein JH. Connective tissue and joint disease in diabetes mellitus. Endocrinol Metab Clin North Am 1996;25:473-83.

25. Kim WK, Kwon SH, Lee SH, Sunwoo IN. Asymptomatic electrophysiologic carpal tunnel syndrome in diabetics: entrapment or polyneuropathy. Yonsei Med J 2000;41:123-7.

26. Nathan PA, Keniston RC, Myers LD, Meadows KD, Lockwood RS. Natural history of median nerve sensory conduction in industry: relationship to symptoms and carpal tunnel syndrome in 558 hands over 11 years. Muscle Nerve 1998;21:711-21.

27. Werner RA, Gell N, Franzblau A, Armstrong TJ. Prolonged median sensory latency as a predictor of future carpal tunnel syndrome. Muscle Nerve 2001;24:14627.

28. Kim SY, Ko MS, Kwon JH, Suh CK. Clinical characteristics of carpal tunnel syndrome in patients with diabetes. J Korean Neurol Assoc 2010;28:277-82.

29. Shun CT, Chang YC, Wu HP, Hsieh SC, Lin WM, Lin $\mathrm{YH}$, et al. Skin denervation in type 2 diabetes: correlations with diabetic duration and functional impairments. Brain 2004;127(Pt 7):1593-605.

30. Obrosova IG. Diabetic painful and insensate neuropathy: pathogenesis and potential treatments. Neurotherapeutics 2009;6:638-47.

31. Kasius KM, Claes F, Verhagen WI, Meulstee J. Ultrasonography in severe carpal tunnel syndrome. Muscle Nerve 2012;45:334-7.

32. Powell HC, Myers RR. Pathology of experimental nerve compression. Lab Invest 1986;55:91-100. 